Empirical Examination of Passing Lane Operational Benefits on Rural Two-Lane Highways. Author(s): Ahmed Al-Kaisy and Zachary Freedman

Source: Journal of the Transportation Research Forum, Vol. 49, No. 3 (Fall 2010), pp. 53-68

Published by: Transportation Research Forum

Stable URL: http://www.trforum.org/journal

The Transportation Research Forum, founded in 1958, is an independent, nonprofit organization of transportation professionals who conduct, use, and benefit from research. Its purpose is to provide an impartial meeting ground for carriers, shippers, government officials, consultants, university researchers, suppliers, and others seeking exchange of information and ideas related to both passenger and freight transportation. More information on the Transportation Research Forum can be found on the Web at www.trforum.org. 


\title{
Empirical Examination of Passing Lane Operational Benefits on Rural Two-Lane Highways
}

\author{
by Ahmed Al-Kaisy and Zachary Freedman
}

This paper presents an empirical investigation into the operational benefits of passing lanes on rural two-lane highways. Two study sites in the state of Montana were used in this investigation. Performance was examined at a single location upstream and multiple locations downstream of the passing lane at each study site. Using percent followers as a performance measure, operational benefits right after the passing lane ranged between $33 \%$ and $42 \%$ at one study site and $12 \%$ to $19 \%$ at the other study site under prevalent traffic levels. Study results also suggest that operational benefits persist for a remarkable distance beyond the end of the passing lane.

\section{INTRODUCTION}

Two-lane highways constitute the vast majority of the highway system in the United States. Those highways are known for higher level of interaction between vehicles traveling in the same as well as in opposing directions. Specifically, passing maneuvers are typically performed using the opposing lane when sight distance and gaps in the opposing traffic stream permit. This has serious implications for traffic operations and safety. From a traffic operations perspective, limited passing opportunities would result in higher impact of slow-moving vehicles on mobility and performance.

As traffic level increases and passing opportunities become more restricted, passing lanes are used in practice as one of the most effective means in providing passing opportunities, thus breaking up platoons and improving operations. In practice, the use of passing lanes is often considered more appropriate than the costly alternative of upgrading to continuous four-lane highway sections. Also, it is a practice to provide passing lanes periodically at regular intervals on long stretches of rural two-lane highways.

For the proper use of passing lanes on two-lane highways, their effect on performance needs to be accurately assessed both at the location of the passing lane and for some distance downstream, i.e., beyond the end of the passing lane. The term "effective length" of passing lane is used by the Highway Capacity Manual (HCM) to refer to the total length of the passing lane and the distance downstream, where the effect of the passing lane persists (TRB 2000). Knowing the operational benefits and the effective length of a passing lane would allow the selection of the most appropriate length and frequency of passing lanes on longer stretches of two-lane highways. In this time of increasing fiscal constraints, this information is critical in achieving optimum use of the limited highway improvement funds.

\section{BACKGROUND}

The HCM 2000 includes a procedure for the analysis of passing lanes on two-lane highway segments (TRB 2000). For two-lane highways, the HCM uses two service measures, percent time-spentfollowing (PTSF) and average travel speed (ATS). PTSF is defined as "the average percentage of travel time that vehicles must travel in platoons behind slower vehicles because of an inability to pass" (TRB 2000). The procedures assume that the PTSF within the passing lane is $58 \%$ to $62 \%$ of its upstream value (value immediately before the passing lane) while ATS within the passing lane is 8 to $11 \%$ higher than its upstream value. Also, the procedure provides values for the effective length of passing lanes, which varies between 3.6 and 13 miles based on traffic volume for PTSF, versus a constant 1.7 miles for ATS. 
While there are quite a few studies on passing lanes in the literature, only a small number of studies attempted to assess the operational benefits and effective length of passing lanes. Most of those studies were largely dependent on traffic simulation, and some used limited field data in the calibration of simulation models. The most relevant of those studies are discussed in this section.

In a relatively recent study (Woolridge et al. 2002), researchers investigated the optimal passing lane length and spacing on two-lane highways. Field data were collected from study sites in Kansas and Minnesota and used later in calibrating the simulation model TWOPAS. Simulation results showed that the percent time-delay (measured as the percentage of headways less than five seconds) decreased as the passing lane length increased. Based on traffic volumes and type of terrain, the optimal length of passing lane varied from 0.8 to 2.0 miles and the optimal spacing between passing lanes varied from 3.5 to 11 miles.

May (1991) used a TRARR traffic simulation model to investigate the operational benefits and the effective length of passing lanes. The results suggested that for passing lanes between 0.52.0 miles in length, benefits tended to diminish after about 2.0 miles. The study also investigated five passing lane locations with different volumes and lengths in California. Overall, passing lanes reduced the percent time-delay and the percentage of headways less than two seconds with the exception of one site where slight increases were observed.

A study by Harwood and Hoban (1987) investigated the optimal length and spacing of passing lanes using simulation. The study used different traffic volumes and lengths of passing lanes, which varied in the range 0.25 mile to 2.0 miles. Results showed that for a flow rate of 400 vehicles per hour (vph) the benefits persisted for at least seven miles from the beginning of the passing lane, while for a flow rate of $700 \mathrm{vph}$ almost all the benefits diminished after five miles. Another earlier study evaluated the effect of passing lanes on operations using the TWOPAS simulation model that was calibrated using field data (Harwood and St. John 1986). The researchers found that the effective length of passing lanes was in the range of three to eight miles. They also found that higher flow rates led to shorter effective lengths. The effective length refers to the total length of the passing lane and the distance downstream, where the effect of the passing lane persists (TRB 2000). The same researchers investigated 12 passing lane sites in several states in an attempt to determine the effective length and spacing of passing lanes (Harwood and St. John 1985). At each site, automatic traffic recorders were placed at locations upstream, within, and up to one mile downstream of the passing lanes where six hours of field data were collected. Using four-second headway or less in identifying platooned vehicles, the study showed that the number of vehicles in a platoon decreased from $35.4 \%$ directly upstream of the passing lane to $20 \%$ within the passing lane. Just downstream of the passing lane the percentage increased to $29 \%$. One mile downstream of the passing lane the number of platooned vehicles was 3.5\% lower than the upstream value. The average platoon length decreased from 2.9 vehicles to 2.7 vehicles before and after the passing lane, respectively.

Mutabazi, Russell, and Stokes (1999) conducted a simulation study to determine the optimum passing-lane configuration to reduce delay. Traffic data were gathered from two sites in Kansas, US-54 and US-50, for calibration of TWOPAS simulation software. The simulation was then used to determine the best configuration of passing lane. The results showed that percent time delay was equivalent for the side-by-side configuration and head-to-head configuration; however, percent delay was higher for all other configurations.

\section{RESEARCH MOTIVATION}

Results from the above mentioned studies show that there is little guidance, if any, in answering the following questions: what are the operational benefits of passing lanes and how far downstream do these benefits persist? The answer to these questions is very important in the planning and design of passing lanes on two-lane highways.

Results from previous studies lack consistency as they varied in too wide of a range to be of any meaningful use. For example, while a study by May (1991) claims that for passing lanes 
between 0.5-2.0 miles in length, benefits tended to diminish after about 2.0 miles. The HCM (TRB 2000) suggests that benefits may exist for 13 miles beyond the passing lane. Other studies suggested different values between the former two values (Harwood and Hoban 1987, Harwood and St. John 1986). Similar inconsistencies exist in the reported benefits of passing lanes that are measured immediately downstream from the passing lane taper. Those inconsistencies may largely be attributed to the following two reasons:

1. The measures of performance used in estimating the benefits of passing lanes in previous studies are not consistent. Specifically, different values for headways were used to identify platooned vehicles by previous research efforts. For example, some studies used three-second headway (Al-Kaisy and Karjala 2008, Gattis et al. 2006), four-second headway (Harwood and St. John 1985), and five-second headway (Woolridge et al. 2002, May 1991; Taylor and Jane 1991, Harwood et al. 1985) in identifying platooned vehicles.

2. The majority of the already limited published research on this topic relied largely on using traffic simulation models. Many of those studies are somewhat outdated and used early versions of simulation models that may not provide realistic results. Further, the difficulty in obtaining appropriate field data may have compromised the necessary validation of these models using field observations.

In light of the above, there is a need to conduct empirical research that would provide a more reliable assessment of passing lane benefits using the performance measures currently used in practice.

\section{PASSING LANE EFFECT ON PLATOONING: THEORETICAL PERSPECTIVE}

This study aims to investigate the effect of passing lanes on two-lane highway operations and the distance downstream of the passing lane where this effect persists, commonly referred to as the passing lane effective length.

Figure 1 shows the hypothesized performance on two-lane highways in the presence of a passing lane. It is somewhat simplistic and very consistent with a similar figure provided in Exhibit 20-22 in the HCM (2000) where the percent time-spent-following is used as a platooning measure. The figure shows the theorized change in platooning level versus position prior, within, and past the passing lane. Upon arriving at the passing lane, traffic on a two-lane highway with restricted

Figure 1: Theoretical Graph Showing Platooning Level Within and Downstream of a Typical Passing Lane on a Two-Lane Highway

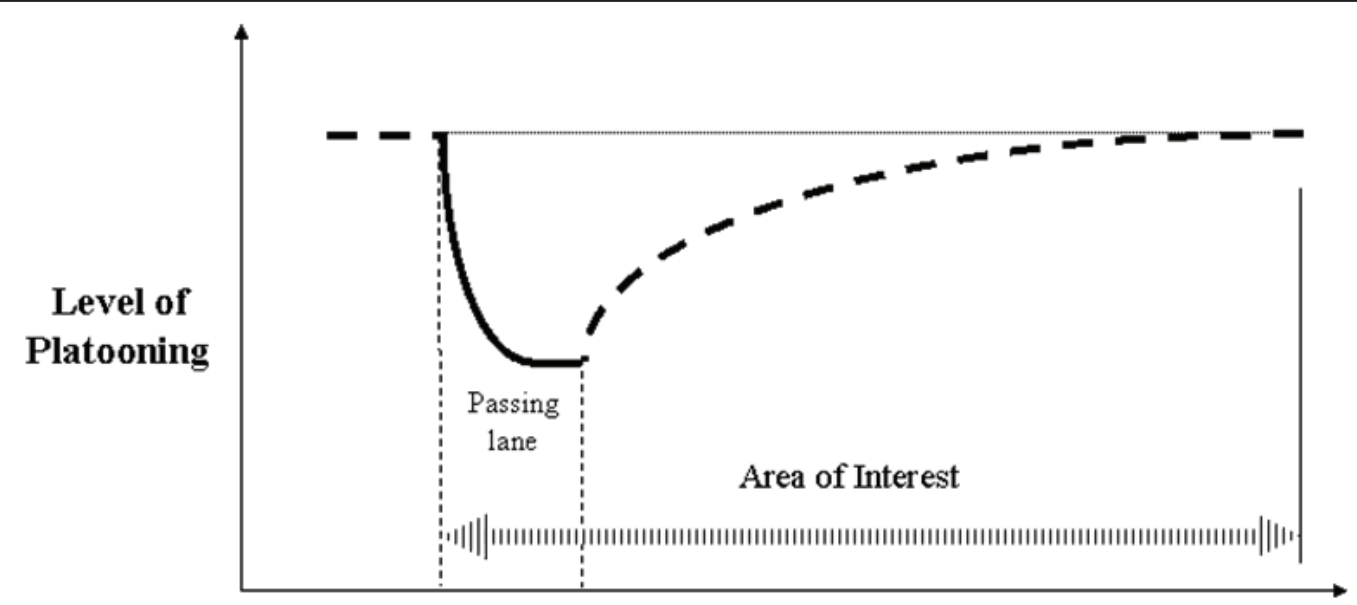

Position Along Highway 
passing opportunities is expected to have a relatively high platooning level. Upon entering the passing lane section, traffic is distributed on the two available lanes, with slower vehicles typically using the passing (right) lane and faster vehicles remaining on the normal (left) lane. This speedbased segregation usually results in passing maneuvers, improved speeds, and decline in platooning level. At the end of the passing lane section, vehicles in the passing lane have to move back into the normal lane, merging with the rest of traffic using a taper.

At this point, all vehicles share again the original travel lane; however, slower vehicles are not necessarily leading platoons at this point. This denotes less impedance to traffic, higher average speeds, and improvement in quality of service. As traffic moves downstream farther from the passing lane, faster vehicles catch up with slower vehicles and platooning level is expected to steadily increase until it eventually reaches its original level (pre-passing-lane value). The stable original level of platooning is based on the assumption that there are no changes in geometric features or passing restrictions throughout the site except for the presence of the passing lane.

\section{STUDY APPROACH}

This study used empirical observations to investigate the effect of passing lanes on platooning and performance on rural two-lane highways. Only highways that are located in rural settings, typically characterized by relatively low volumes and high speeds, are considered within the scope of this study. Further, climbing lanes (passing lanes on extended upgrades) are considered beyond the scope of the study.

The study approach required the selection of passing lane sites where the passing lane and a significant distance downstream are free from major access points and are generally located in level terrain. Several data collection stations were installed upstream and at various distances downstream of the passing lane using automatic traffic recorders. Three performance measures were estimated to discern the effect of the passing lane and the change in that effect as traffic traverses and moves away from the passing lane. Those performance measures are:

1. Percent Followers: Percent followers represent the percentage of vehicles with short headways in the traffic stream. Specifically, a follower is a vehicle following another vehicle in the traffic stream with a short headway in between. This performance indicator can easily be measured in the field and as such is used by the HCM as a surrogate measure for PTSF field estimation. The headway cut-off value used by the current HCM is three seconds, which is the same value used in this study.

2. Follower Density: Follower density is the number of followers in a directional traffic stream over a unit length such as a mile or a kilometer. It is estimated as the product of density and percent followers, as in the following equations:

(1) Follower Density $=$ Density * Percent Followers

(2) Follower Density $=($ Hourly Flow Rate $/$ Average Speed $) *(\%$ Headways $<$ three seconds $)$

The argument behind using this performance indicator is that a road with low average daily traffic (ADT) and high PTSF should have a lower level of service (LOS) than the same road with a higher ADT and PTSF equal to the low ADT road (Van As 2003). This is particularly true in the context of highway improvement decision making for which the LOS and other operational analyses are important inputs.

3. Average Travel Speed as a Percentage of Free-Flow Speed (ATS/FFS): This is an indicator of the amount of speed reduction due to platooning on two-lane highways. In the context of this research, if the percentage is high, then the interaction among successive vehicles in the traffic stream is small, and a low platooning level is expected. By the same token, a lower percentage indicates a higher level of platooning.

For details on the above measures, please refer to a recent study on two-lane highway performance measures (Al-Kaisy and Karjala 2008). 


\section{DATA COLLECTION AND REDUCTION}

To investigate the effect of passing lanes on a platooning level, it was necessary to consider the following criteria in the selection of study sites:

1. No major driveways or intersections exist within the passing lane and for some distance upstream and downstream.

2. As practically as possible, the site should be free of tangible grades (grades greater than $2 \%$ ) or other features that are believed to affect platooning on two-lane highways.

3. The site should possess geometric features that are considered typical for other passing lanes on rural two-lane highways.

The above criteria followed in the selection of study sites made it difficult to identify appropriate sites for this study. Upon examining seven candidate sites, only two sites largely met the criteria above and were therefore selected for the study. As-built roadway drawings, video logs, and Google earth images were all used in screening candidate study sites.

Study Site I. This site is located on Highway US 287 between the towns of Three Forks and Townsend in the state of Montana. Townsend is approximately 5.5 miles upstream of this site and therefore the impact of any traffic interruption on platooning is considered minimal, if any. The total length of the site is about 8.25 miles including the length of the passing lane, which is approximately 1.5 miles (including tapers). The major merit of this site is the relatively long distance downstream that met the selection criteria. Traffic level at this site is relatively low.

Study Site II. This site is located on Highway US 191 just north of the Gallatin canyon in southwest Montana. The upstream end of this site is about 30 miles from the nearest intersection, and as such no effect on platooning is expected. The total length of this site is approximately 2.5 miles including the length of the passing lane, which is about 0.9 miles (including tapers). The distance downstream is limited to 1.5 miles, which is relatively short. However, traffic level at this site is notably higher than that at the US-287 site, which is important to this investigation.

Data collection setups at the two study sites are shown in Figure 2. Seven data collection stations were installed at the US-287 site versus four stations at the US-191 site. The first station at both sites is located 250 feet upstream of the passing lane. As applicable, the other stations are located at roughly 250 feet, 0.5 miles, 1.5 miles, 3 miles, 5 miles, and 6.6 miles downstream of the passing lane, respectively. The distances mentioned were measured from the end of the passing lane tapers. Automatic traffic recorders were used to measure traffic counts, individual vehicle speeds, vehicle classification, and headways.

Data were collected over a one-week period in May 2008. Due to a malfunction in the traffic recorder at the upstream station at the US-287 site, additional data from the upstream and downstream stations were collected over a one-week period in June 2008. A total of 1,583 hours (about 66 days) of traffic records with more than 222,000 observations were collected at the two study sites.

Traffic records were thoroughly screened to make sure that any defective data were eliminated from the data sets. Also, to avoid any possible effect of light condition and rain on performance measures, only daytime periods with dry weather were used in this study. 
Figure 2: Data Collection Setup (a) US 287 Study Site (b) US 191 Study Site

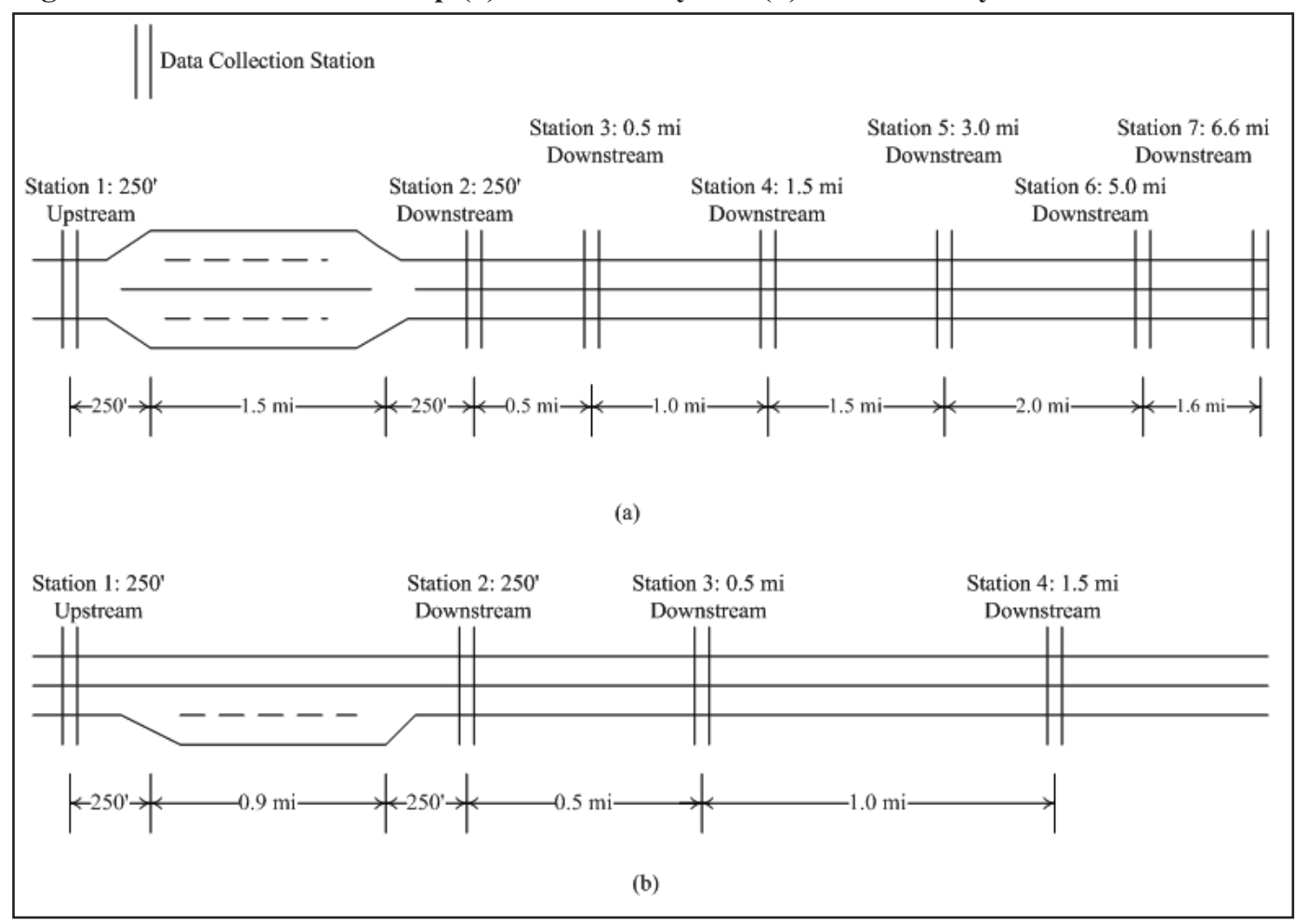

\section{STUDY RESULTS}

The hypothesized platooning level graph shown in Figure 1 was tested using analyses that aim at exploring the association between performance, the presence of passing lane, and the distance past the end of the passing lane. The terms "platooning" and "performance" will be used interchangeably in the following sections. While two sites were used in this study, only the US-287 site was used throughout the analysis. The other site, the US-191, was used for the preliminary examination and analysis of headway distribution only. The main reason for not including the US-191 site in the statistical analyses is that this site did not allow the investigation of adequate distance downstream of the passing lane, which was necessary for examining the effect of the passing lane on platooning.

\section{Preliminary Examination}

The first step in testing the research hypothesis was to examine performance measures at data collection stations to discern trends in platoon dispersion and formation as related to the presence of passing lanes.

To assess the immediate effect of the passing lane on performance, a comparison of performance measures between the upstream and downstream stations is provided in Table 1. Traffic levels at the two sites were established based on the observed traffic volumes at the two study sites. Upon carefully examining this table, the following observations can be made. 
Table 1: Changes in Performance Measures over the Passing Lanes at Study Sites

\begin{tabular}{|c|c|c|c|}
\hline \multicolumn{4}{|c|}{ US 287 Site } \\
\hline Performance Measure & Upstream & Downstream & Percent Change \\
\hline \multicolumn{4}{|c|}{ Average Hourly Volume $=130 \mathrm{vph}$} \\
\hline Percent Followers & 36.3 & 21.4 & -41.05 \\
\hline Follower Density & 0.697 & 0.400 & -42.67 \\
\hline ATS/FFS & 0.98 & 0.99 & 0.81 \\
\hline \multicolumn{4}{|c|}{ Average Hourly Volume $=155 \mathrm{vph}$} \\
\hline Percent Followers & 40.8 & 27.1 & -33.58 \\
\hline Follower Density & 0.922 & 0.564 & -38.83 \\
\hline ATS/FFS & 0.98 & 0.96 & -1.43 \\
\hline \multicolumn{4}{|c|}{ US 191 Site } \\
\hline Performance Measure & Upstream & Downstream & Percent Change \\
\hline \multicolumn{4}{|c|}{ Average Hourly Volume $=110 \mathrm{vph}$} \\
\hline Percent Followers & 25.32 & 21.03 & -16.94 \\
\hline Follower Density & 0.37 & 0.33 & -11.71 \\
\hline ATS/FFS & 0.984 & 0.969 & -1.52 \\
\hline \multicolumn{4}{|c|}{ Average Hourly Volume $=200 \mathrm{vph}$} \\
\hline Percent Followers & 38.79 & 31.49 & -18.82 \\
\hline Follower Density & 1.04 & 0.888 & -14.62 \\
\hline ATS/FFS & 0.987 & 0.948 & -3.95 \\
\hline \multicolumn{4}{|c|}{ Average Hourly Volume $=330 \mathrm{vph}$} \\
\hline Percent Followers & 53.31 & 46.61 & -12.57 \\
\hline Follower Density & 2.45 & 2.28 & -6.94 \\
\hline ATS/FFS & 0.984 & 0.954 & -3.05 \\
\hline
\end{tabular}

1. The percent changes in performance measures are greater at the US-287 site relative to the US191 site. This is consistent with the fact that the passing lane at the US-287 site is considerably longer than that at the US-191 site.

2. The headway-related measures, i.e., percent followers and followers' density, have shown remarkable improvements at the two study sites under various traffic conditions. These improvements are more notable at lower traffic levels.

3. Changes in the third performance measure (ATS/FFS) are relatively small particularly at lower traffic levels.

To examine the part of the platooning graph beyond the passing lane, the three performance measures were plotted at various stations downstream of the passing lane as shown in Figure 3.

The following important trends are clearly exhibited in this figure:

1. Percent followers and follower density exhibit improvement in performance for a relatively short distance downstream of the passing lane. While this trend applies to the two study sites, it is more evident at the US-287 site, where a considerable downstream distance was investigated. Also, the improvement is somewhat more notable at higher traffic levels. 
Passing Lane Operational Benefits

2. Beyond the 1.5 mile station (US-287 site), platooning level increases steadily as traffic moves away from the passing lane. This trend is common to all performance measures used in this study.

3. The increase in platooning level in these graphs does not flatten out or reach a plateau as suggested by the hypothesized platooning curve. This may be an indication that the operational benefits of the passing lane continue well beyond 6.6 miles, the farthest distance investigated in this research.

Figure 3: Change in Performance Measures Downstream of Passing Lanes at Study Sites
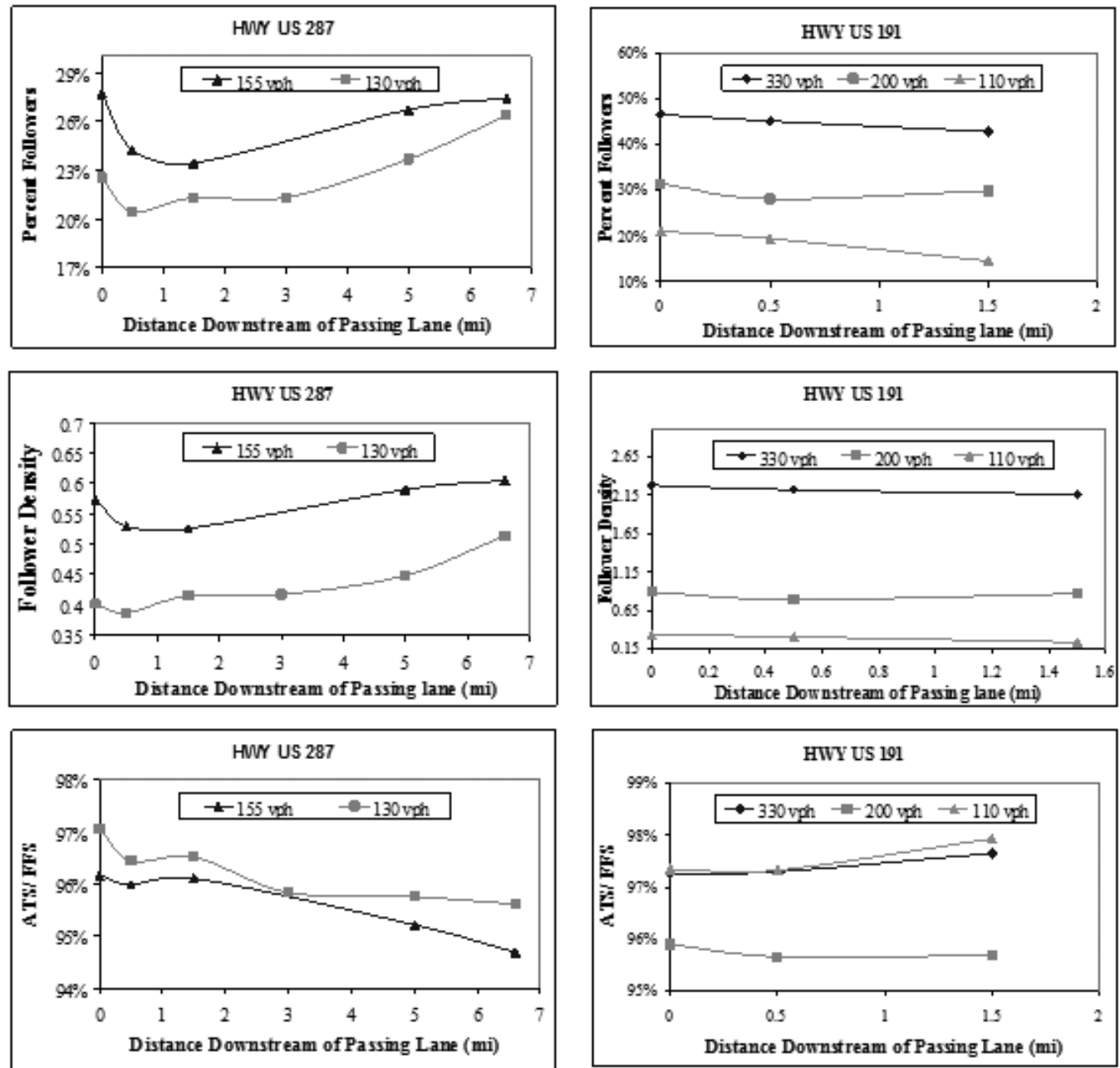
While the first observation may initially sound unexpected, it can easily be understood if one thinks about the dynamics of breaking up platoons by passing lanes more at the microscopic level. Initially, vehicles arrive at the passing lane location with relatively high level of platooning. As vehicles enter into the passing lane, a portion of vehicles, including the slower moving vehicles, usually take the passing (right) lane. This maneuver normally takes place at the taper location, but some vehicles may change lanes later into the passing lane section. This will allow faster vehicles on the normal (left) lane to travel at higher speeds, not impeded by the once platoon leaders, the slower moving vehicles. Eventually, many of the faster vehicles will pass the slower vehicles within the passing lane. As the passing lane comes to an end, vehicles in the passing lane have to merge back into the normal lane. This merge activity creates short headways, as many vehicles are forced to accept shorter headways moving back into the normal lane. Those vehicles may need to adjust their speed, which is normal in a similar merge situation. As a result, platooning level (denoted by the presence of short headways) becomes "relatively" high right after the passing lane. However, platoons at the downstream end of the passing lane are different in attributes from those at the upstream end, as the former are largely associated with the aforementioned merge activity, while the latter are mostly associated with slower vehicles impeding the movement of faster vehicles. As vehicles move farther from the passing lane, some vehicles adjust the short headways to their comfort level, thus reducing the percentage of short headways and hence platooning level. This activity takes place over a short distance beyond the passing lane, which could be a function of traffic level. On the other hand, the impedance of slower vehicles to faster vehicles, which was largely diffused by the passing lane, starts to build up again as vehicles move farther from the passing lane and faster vehicles eventually catch up with the slower vehicles. This explains the increase in platooning level at the stations beyond the 1.5 -mile station at the US-287 site.

To better understand the magnitude of change of performance measures as traffic moves farther from the passing lane, the percent of change for each performance measure is plotted downstream of the passing lane at the US-287 site as shown in Figure 4. While the change in the ratio of average speed to free-flow speed is minimal, changes in headway-related measures are quite notable. This indicates that the headway-related measures investigated are more sensitive to platooning on twolane highways than the speed ratio.

Table 2 shows the difference in performance between the upstream station and the farthest downstream station at the US-287 site using headway-related performance measures. The figures presented in this table show that the residual operational benefits at 6.6 miles downstream of the passing lane are fairly high. This suggests that the effective length of the passing lane could extend a considerable distance beyond the location of this station.

Table 2: Residual Operational Benefits at 6.6-Miles Station (US-287 Study Site)

\begin{tabular}{c|c|c|c}
\hline \multicolumn{4}{c}{ Average Hourly Volume $=\mathbf{1 3 0}$ vph } \\
\hline Performance Measure & Upstream & $\begin{array}{c}\mathbf{6 . 6} \text { miles } \\
\text { Downstream }\end{array}$ & Residual Benefits \\
\hline Percent Followers & 36.3 & 25.8 & $28.93 \%$ \\
\hline Follower Density & 0.697 & 0.510 & $26.85 \%$ \\
\hline \multicolumn{4}{c}{ Average Hourly Volume $=\mathbf{1 5 5}$ vph } \\
\hline Performance Measure & Upstream & $\begin{array}{c}\mathbf{6 . 6} \text { miles } \\
\text { Downstream }\end{array}$ & Residual Benefits \\
\hline Percent Followers & 40.8 & 27.7 & $32.11 \%$ \\
\hline Follower Density & 0.922 & 0.617 & $33.08 \%$ \\
\hline
\end{tabular}


Passing Lane Operational Benefits

Figure 4: Percent Change in Performance Measures Downstream of the Passing Lane at US-287 Study Site
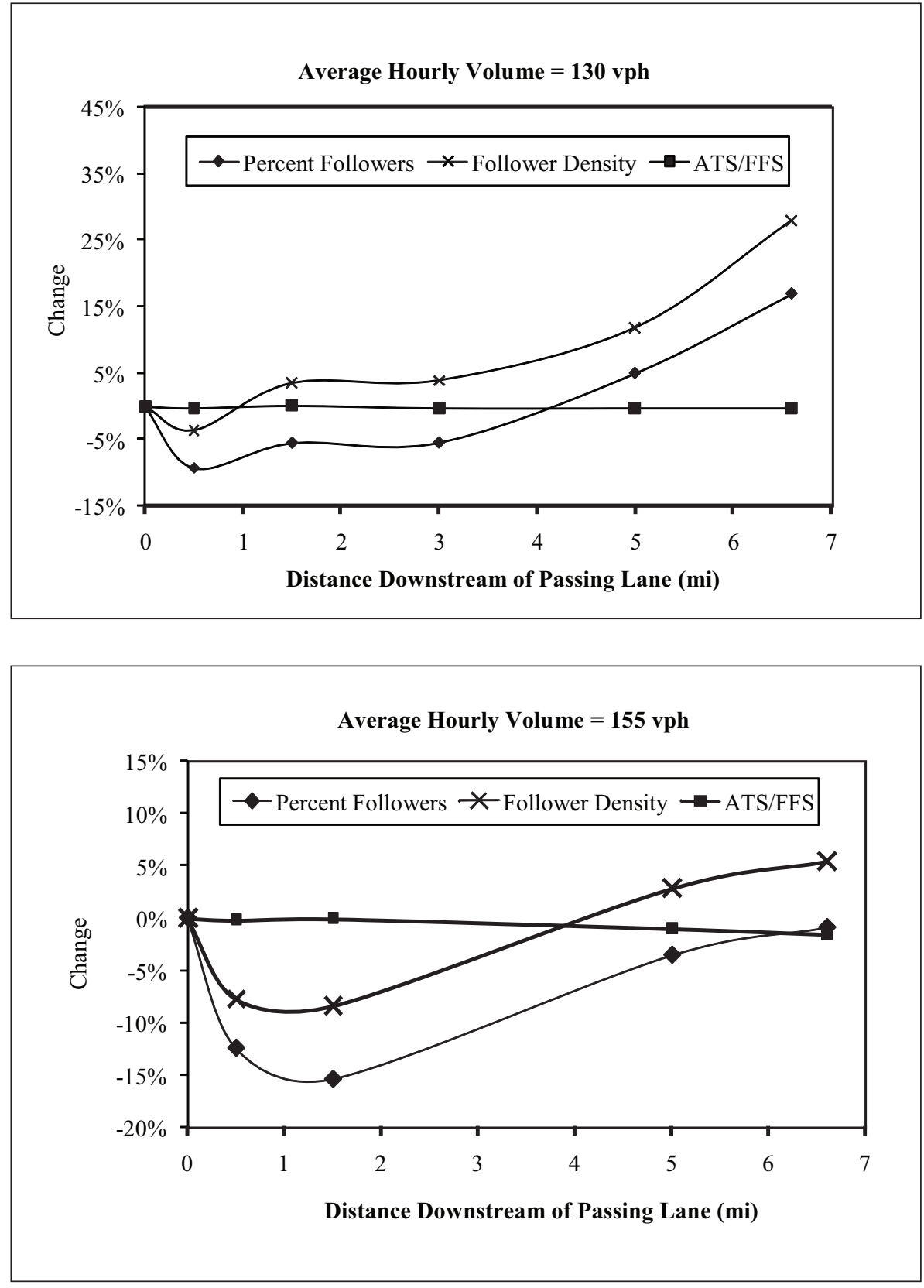


\section{Examination of Headway Distribution}

As platooning is directly related to headways, headway distributions were plotted at the two study sites using a three-interval scheme as shown in Figure 5. Upon examining this figure, it is evident that short headways (less than three seconds) have dropped remarkably at the downstream station in comparison with that just before the passing lane at the two study sites.

However, there is sufficient evidence that the actual improvement in performance could be even greater if one considers the merge effect and its associated short headways as discussed earlier. This explains the further decrease in short headways over the following station(s): 0.5 -mile station at the two study sites and 1.5-mile station at the US-287 site. Beyond this point, the percentage of short headways generally increases, indicating an increase in the platooning level.

Figure 5: Headway Distribution at Data Collection Stations at Study Sites
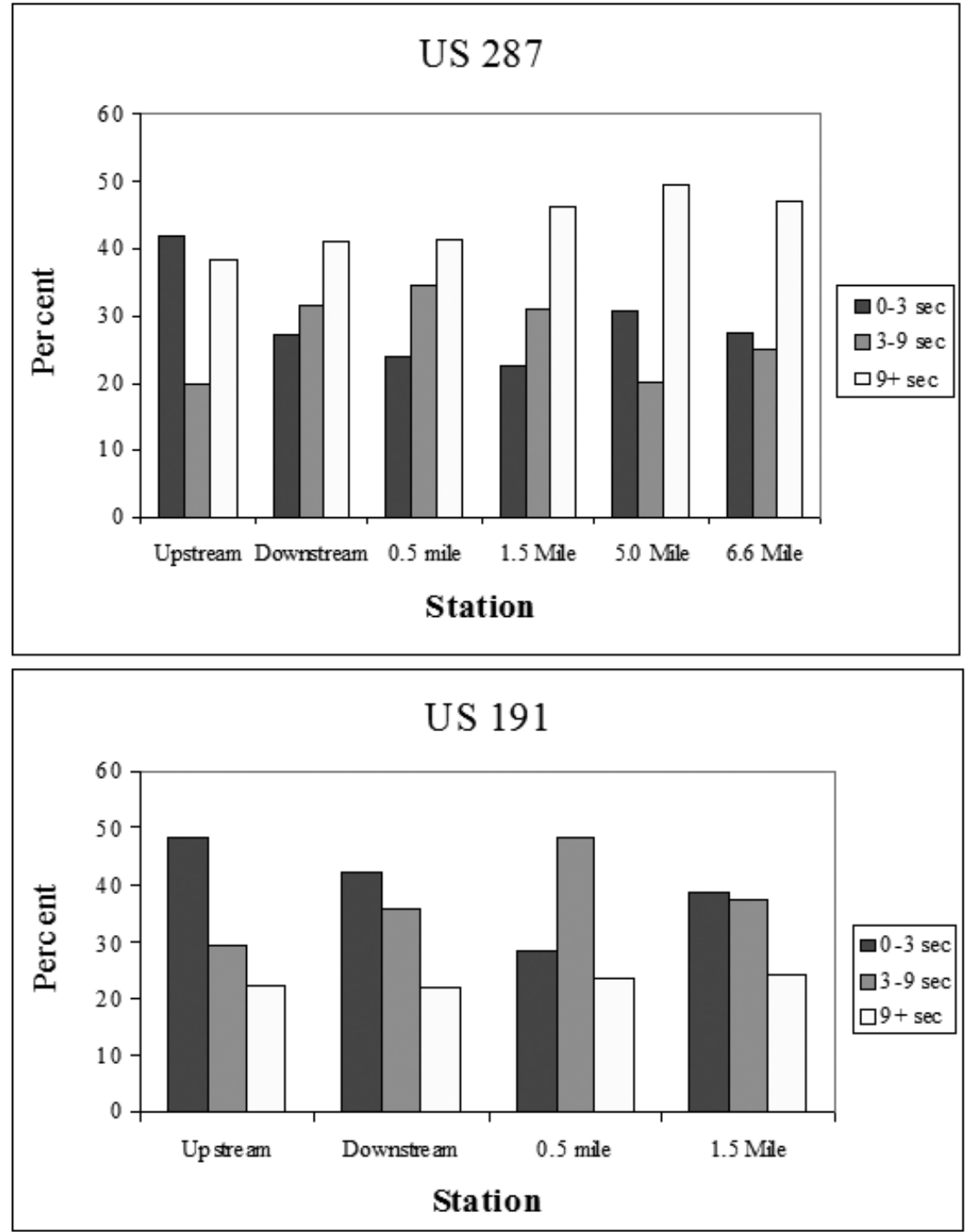
At the US-287 site, this percentage remains lower than the original percentage at the upstream station. This may well indicate that, for the traffic level investigated, operational benefits of the passing lane persist for a distance longer than the distance investigated in this research (6.6 miles). On the other hand, the percentage of long headways (nine seconds or greater) generally increases, and the medium size headways (three to nine seconds) decreases beyond the downstream station. This may indicate an increased level of vehicle segregation into platooned and non-platooned vehicles and hence into longer and shorter headways. At the US-191 site, trends are consistent with their counterparts at the US-287 site for the limited distance investigated downstream of the passing lane.

\section{Statistical Analysis}

To examine the effect of distance downstream of the passing lane on platooning and performance, data from the US-287 site were further analyzed to get a better understanding of their association. Data from the US-191 site were not used in the statistical analysis due to the short downstream distance investigated by this study. Table 3 provides the coefficients of correlation among the three performance measures and all "platooning" variables, including the distance downstream of the passing lane, referred to as "distance" in the table. The percentage trucks refers to the percentage of heavy vehicles in the traffic stream. The merge effect refers to the effect of merge activity on headways and platooning that only exists at the data collection station immediately downstream of the passing lane. It is included in this analysis as an indicator (dummy) variable. An indicator variable is one that takes the values 0 or 1 to indicate the absence or presence of some effect, in this case the merge activity, which may be expected to shift the outcome. While the study site is generally located in level terrain, the exact percentage grade from as-built drawings at various data collection stations was used in the analysis. Percent no passing in this study refers to the percentage of length of highway where passing is prohibited within one mile upstream of the data collection station.

Table 3: Correlation Coefficients Between Performance Measures and Major Platooning Variables

\begin{tabular}{c|c|c|c|c|c|c}
\hline \multicolumn{7}{c}{ US 287 } \\
\hline Performance Indicator & Volume & $\begin{array}{c}\text { \% No } \\
\text { Passing }\end{array}$ & Distance & $\begin{array}{c}\text { Merge } \\
\text { Effect }\end{array}$ & Grade & $\begin{array}{c}\% \\
\text { Trucks }\end{array}$ \\
\hline Percent Followers & 0.800 & ----- & 0.169 & ---- & ----- & 0.109 \\
\hline Follower Density & 0.832 & ----- & ----- & 0.104 & ----- & ----- \\
\hline ATS/FFS & -0.744 & ----- & -0.248 & 0.145 & -0.194 & ----- \\
\hline
\end{tabular}

Note: Cells marked with “------" refer to coefficient of correlation less than 0.1.

The results show that traffic volume has the highest correlation with performance measures (all coefficients are above 0.74). The results also suggest a weak correlation among the three performance measures and other platooning variables, including the distance downstream of the passing lane. Overall, the percent-no-passing showed the lowest correlations with the three performance measures. All correlation coefficients exhibited logical relationships, i.e., platooning increases with the increase in traffic volume, grade, distance downstream of passing lane, percentage trucks, and the presence of merge effect.

To get a closer look at the association between performance measures and distance downstream of the passing lane, it was deemed appropriate to control the effect of volume in the analysis. As such, the analysis of correlations was repeated using data that roughly reflects the same traffic level. The new data set only involves hourly volumes that are in the range $125 \mathrm{vph}$ to $135 \mathrm{vph}$, 
which constitute the majority of the observations. At this traffic level, the correlation coefficients were calculated between performance measures and all other platooning variables as shown in Table 4. This time, the distance downstream of the passing lane showed relatively high correlations with performance measures as shown in this table (all coefficients are above 0.73). All distance coefficients exhibited logical relationships with performance measures. Specifically, as the distance downstream of the passing lane increases, percent followers and follower density increase as well. On the other hand, as this distance increases, the ratio of average travel speed to the free-flow speed decreases. Only one illogical (and low) correlation coefficient was found between follower density and percent no-passing. What this tells us is that follower density was not reasonably sensitive to percent no-passing at this study site. In case studies where a specific site is investigated, it is likely to have an illogical weak correlation given the amount of field data used and the many variables that could affect the measure of interest.

Table 4: Correlation Coefficients Between Performance Measures and Platooning Variables at Same Traffic Level

\begin{tabular}{c|c|c|c|c|c}
\hline \multicolumn{7}{|c}{ US 287 } \\
\hline Performance Indicator & \% No Passing & Distance & $\begin{array}{c}\text { Merge } \\
\text { Effect }\end{array}$ & Grade & \% Trucks \\
\hline Percent Followers & ----- & 0.732 & ---- & 0.338 & 0.189 \\
\hline Follower Density & $(-0.233)$ & 0.735 & 0.139 & 0.21 & 0.197 \\
\hline ATS/FFS & -0.399 & -0.94 & 0.711 & -0.68 & 0.579 \\
\hline
\end{tabular}

Note: Cells marked with "------" refer to coefficient of correlation less than 0.1

Values in brackets are those that exhibited illogical relationships

Besides correlation coefficients, multivariate linear regression, another tool used to explore linear relationships, was also performed to examine the functional relationships between performance indicators and platooning variables with special emphasis on the distance downstream of the passing lane.

Table 5 summarizes the results of the regression analysis, which show the relationship between the response variable (performance indicators) and predictor (platooning) variables. Upon examining this table, the following observations can be made:

1. All three models are significant at the $95 \%$ confidence level as affirmed by the F-test results.

2. The coefficients of determination (R-square) are relatively high, which shows that much of the variation in the performance measures is explained by the respective models. Traffic volume and distance downstream of the passing lane were found significant in all regression models.

3. This indicates that distance beyond the end of the passing lane has significant effect on all performance measures investigated in this study. Merge effect and percent no-passing were found only significant in the model for estimating percent followers.

4. Grade was found insignificant in all regression models, which shows that it had no tangible effect on any of the performance measures. This is mainly due because the study site is located in generally level terrain and the amount of changes in grade among data collection stations was minimal.

5. All predictor variables that were found significant using the t-test exhibited logical relationships with the dependent variable. 
Table 5: Results from Multivariate Linear Regression Analysis at Study Site US 287

\begin{tabular}{|c|c|c|c|c|c|c|c|c|c|}
\hline \multicolumn{10}{|c|}{ US 287} \\
\hline \multirow{2}{*}{$\begin{array}{l}\text { Performance } \\
\text { Indicator }\end{array}$} & \multicolumn{3}{|c|}{ Regression Model } & \multicolumn{6}{|c|}{ Coefficient and $\mathrm{P}$-value from $\mathrm{t}$-test ${ }^{2,3}$} \\
\hline & $\begin{array}{l}\text { P value } \\
\text { F-test }^{1}\end{array}$ & $\begin{array}{c}\text { R- } \\
\text { squared }\end{array}$ & SE & Volume & $\begin{array}{l}\% \text { No } \\
\text { Passing }\end{array}$ & $\begin{array}{c}\% \\
\text { Trucks }\end{array}$ & Dist & $\begin{array}{l}\text { Merge } \\
\text { Effect }\end{array}$ & Grade \\
\hline Percent Follower & $\leq 0.001$ & 0.74 & 2.66 & $\begin{array}{l}0.0741 \\
<0.001\end{array}$ & $\begin{array}{c}0.0323 \\
0.01\end{array}$ & $\begin{array}{l}0.055 \\
(0.09)\end{array}$ & $\begin{array}{c}0.789 \\
<0.001\end{array}$ & $\begin{array}{r}3.42 \\
<0.001\end{array}$ & $\begin{array}{c}0.626 \\
0.43\end{array}$ \\
\hline Follower Density & $\leq 0.001$ & 0.72 & 0.09 & $\begin{array}{c}0.00023 \\
<0.001\end{array}$ & $\begin{array}{c}0.00002 \\
0.76\end{array}$ & $\begin{array}{c}-0.0154 \\
0.92\end{array}$ & $\begin{array}{c}0.0122 \\
0.02\end{array}$ & $\begin{array}{r}0.0877 \\
(\mathbf{0 . 0 8})\end{array}$ & $\begin{array}{c}-0.0081 \\
0.76\end{array}$ \\
\hline ATS/FFS & $\leq 0.001$ & 0.67 & 0.77 & $\begin{array}{c}0.00008 \\
<0.001\end{array}$ & $\begin{array}{c}-0.0012 \\
0.78\end{array}$ & $\begin{array}{c}0.201 \\
0.59\end{array}$ & $\begin{array}{l}-0.174 \\
<0.001\end{array}$ & $\begin{array}{c}-0.048 \\
0.20\end{array}$ & $\begin{array}{c}-0.194 \\
0.11\end{array}$ \\
\hline
\end{tabular}

${ }_{2}^{1}$ Values underlined in italic refer to models that were found significant using the F-test

${ }_{3}^{2}$ Values in bold are for coefficients that were found significant using the t-test

${ }^{3}$ Values in brackets are those that passed significance testing at the $90 \%$ confidence level only

To further examine the effect of distance on performance measures, another regression analysis was conducted where all variables that were found less important were dropped from further analysis. This has narrowed the list of variables to traffic volume and distance downstream of the passing lane. To control for the effect of volume, only field data that roughly represents the same traffic level (125-135 vph) were used in the regression. This allowed dropping volume from the regression analysis leaving distance as the only predictor variable.

The objective is to answer the question: for a given traffic volume, what is the effect of distance on traffic performance and platooning? The results are presented in Table 6. Upon examining the F-test and t-test results, it is evident that the three models are significant at the $95 \%$ confidence level. Also, the only predictor variable, distance downstream of the passing lane, was found significant in all three models. The R-square values suggest that distance explained approximately $54 \%$ of the variation in percent followers and follower density and approximately $89 \%$ of the variation in the speed ratio. These results are generally consistent with those from the correlation analysis.

Table 6: Results from Multivariate Linear Regression Analysis with Distance as the Only Predictor Variable

\begin{tabular}{c|c|c|c|c}
\hline \multirow{2}{*}{ Performance Indicator } & \multicolumn{3}{|c}{ Regression Model } & P-value from t-test \\
\cline { 2 - 5 } & F-test & R-squared & SE & Distance \\
\hline Percent Follower & $<0.001$ & 0.536 & 1.598 & $<0.001$ \\
\hline Follower Density & $<0.001$ & 0.540 & 0.023 & $<0.001$ \\
\hline ATS/FFS (\%) & $<0.001$ & 0.887 & 0.175 & $<0.001$ \\
\hline
\end{tabular}

\section{CONCLUDING REMARKS}

Most studies in the literature either relied heavily on simulation or investigated a short distance downstream of the passing lane. Therefore, there were conflicting findings in the literature in regards to the distance where the effect of the passing lane persists, also called the effective length of the passing lane. The current research utilized empirical data to investigate the effect of passing 
lanes on rural two-lane highways. Analyses were conducted to assess the operational benefits of passing lanes and how those benefits diminish as traffic moves away from the passing lane. The major findings of this study are:

1. Using headway-related performance measures, platooning level decreases beyond the downstream end of the passing lane for a short distance before it starts to increase again as traffic moves away from the passing lane. For the study sites investigated, results suggest that this distance could be as long as 1.5 miles beyond the end of passing lane taper. This phenomenon is related to the merge activity at the end of the passing lane, which may force many drivers to accept headways shorter than what they would comfortably select. This shows a limitation in using the headway-related performance measures as indicators of platooning and impedance on two-lane highways.

2. Despite the effect of the merge activity, the change in headway-related performance measures before and after the passing lane is notable in most instances and is a function of passing lane length and traffic level. Changes in headway-related performance measures ranged between $33 \%$ and $43 \%$ at the US-287 site versus $7 \%$ and $19 \%$ at the US-191 site. The true improvement in performance caused by the passing lane is expected to exceed these values should the merge effect discussed earlier be considered.

3. Research results showed considerable residual operational benefits (around $30 \%$ reduction in platooning level) at 6.6 miles downstream of the passing lane at the US-287 study site. This suggests that the passing lane operational benefits at this site may well persist for a few more miles beyond the distance investigated, and consequently the effective length is likely to be in the order of 10 miles (or even longer). This finding may contradict other studies in the literature, but it is somewhat consistent with the value of the passing lane effective length provided in the current HCM. Specifically, the HCM suggests that the passing lane benefits in breaking up platoons could persist for up to 13 miles depending on traffic volumes. While this study could not examine platooning for such a long distance, the residual benefits at 6.6 miles suggest that such benefits may persist well beyond the distance investigated in this research.

Given the many variables that could affect the passing lane effective length, the authors strongly recommend further empirical studies on passing lanes which consider other ranges of traffic volumes and passing lane lengths. This will help to develop a better understanding of the operational benefits of passing lanes, which is critical in the proper planning and design of passing lanes on rural twolane highways.

\section{Acknowledgements}

The authors would like to acknowledge the financial support to this research by the Western Transportation Institute of Montana State University.

\section{References}

Al-Kaisy, A. and S. Karjala. "Indicators of Performance on Two-Lane Rural Highways: An Empirical Investigation." Transportation Research Record 2071, (2008): 87-97.

Gattis, J., R. Bhave, and L. Duncan. “Alternating Passing Lane Length.” Transportation Research Record 1961, (2006): 16-23.

Harwood, D. and C. Hoban. "Low Cost Methods of Operational Improvements on Two-Lane Highways.” Midwest Research Institute. Report No. FHWA/IP-87/2, 1987.

Harwood, D. and A. St. John. "Operational Effectiveness of Passing Lanes on Two Lane Highways." Federal Highway Administration, Report No. FHWA/RD-86/195, 1986. 
Passing Lane Operational Benefits

Harwood, D. and A. St. John. "Passing Lanes and Other Operational Improvements on Two-Lane Highways.” Federal Highway Administration, Report No. FHWA-RD-85-028, 1985.

May, A. "Traffic Performance and Design of Passing Lanes." Transportation Research Record 1303, (1991): 63-73.

Mutabazi, M., E. Russell, and R. Stokes. "Review of the Effectiveness, Location, Design, and Safety of Passing Lanes in Kansas.” Transportation Research Record 1658, (1999): 25-33.

Taylor, W. and M. Jain. "Warrants for Passing Lanes." Transportation Research Record 1303, (1991): 83-91.

Transportation Research Board. Highway Capacity Manual. Fourth Edition. TRB, National Research Council, Washington, D.C., 2000.

Van As, C. "The Development of an Analysis Method for the Determination of Level of Service on Two-Lane Undivided Highways in South Africa." Project Summary. South African National Roads Agency, 2003.

Woolridge, M., C. Messer, B. Heard, S. Rughupathy, A. Parham, M. Brewer, and S. Lee. "Design Criteria for Improved Two-Lane Section (Super 2).” Texas Transportation Institute, Project Report 0-4064, 2002.

Dr. Ahmed Al-Kaisy is an associate professor and the principal transportation faculty member in the Department of Civil Engineering at Montana State University. He is also program manager for the Safety and Operations Focus Area at the Western Transportation Institute and a registered professional engineer in the state of Montana. Dr. Al-Kaisy received a Ph.D. degree in transportation engineering from Queen's University in Ontario, Canada.

Zachary Freedman received an M.Sc. degree in transportation engineering from Montana State University in 2009, and a B.Sc. in civil engineering from the University of Utah in 2007. His graduate research was in the area of traffic performance on two-lane highways. He currently works as a transportation engineer with the South Dakota Department of Transportation. 